\title{
Colorectal Cancer Screening Practices among Obstetrician/Gynecologists and Nurse Practitioners
}

\author{
Stacy B. Menees, M.D., Divya A. Patel, Ph.D., M.P.H., ${ }^{2}$ and Vanessa Dalton, M.D., M.P.H. ${ }^{2}$
}

\begin{abstract}
Objective: Obstetrician/gynecologists (Ob/Gyn) and nurse practitioners (NP) are essential providers of primary and preventive care for their female patients. Therefore, colorectal cancer (CRC) screening should be part of their routine preventive practices. The purpose of our study is to evaluate the CRC screening practices of these providers.

Methods: A self-administered survey was mailed to a national sample of $1130 \mathrm{Ob} / \mathrm{Gyns}$ and NPs to assess providers' demographics, current CRC screening practices, and familiarity with CRC guidelines.

Results: Three hundred thirty-six providers (29.7\%) returned our survey (54\% Ob/Gyns and $46 \% \mathrm{NPs})$. Three fourths of providers routinely performed screening for CRC, compared with $95 \%$ for breast and cervical cancer. Routine CRC screening was more common among Ob/Gyns $(87.2 \%)$ than NPs $(61.7 \%)(p<0.001)$. Slightly over half of providers correctly identified the recommended age to begin CRC screening for the average-risk patient, with no significant difference between provider types. Overall, Ob/Gyns scored higher than NPs on a series of questions assessing CRC screening $(p<0.03)$. Several provider factors were found to be significantly associated with screening practices, including practicing $>10$ years $(p<0.01)$, practicing in a multispecialty group $(2.62$ times more likely), and having an older patient population $(p<0.001)$.

Conclusions: $\mathrm{Ob} / \mathrm{Gyns}$ and NPs underuse CRC screening compared with breast and cervical cancer screening and lack knowledge about appropriate use of CRC screening modalities. Opportunities to further educate $\mathrm{Ob} / \mathrm{Gyns}$ and NPs should be sought to improve compliance with current CRC screening guidelines.
\end{abstract}

\section{Introduction}

$\mathrm{C}$ OLORECTAL CANCER (CRC) is the third leading cause of cancer and cancer-related deaths in women. ${ }^{1}$ In 2007, there will be an estimated 74,630 new diagnoses of colorectal cancer and 26,180 associated deaths in women. ${ }^{1}$ The current recommended CRC screening tests for cancer prevention and cancer detection based on the most recent U.S. multisociety task force guidelines (American College of Gastroenterology, American College of Gastrointestinal Endoscopy, American College of Physicians/Society of Internal Medicine, and American Cancer Society) include colonoscopy every 10 years; flexible sigmoidoscopy, CT colonography, or barium enema every 5 years; yearly fecal occult blood test (FOBT) or fecal immunohistochemical test; and stool DNA, interval unknown. ${ }^{2}$ Despite these recommendations, CRC screening compliance among patients remains low. Data from the National Behavioral Risk Factor Surveillance System (BRFSS) in 2004 demonstrated only a 57\% adherence rate for all CRC screening modalities. ${ }^{3}$

Women are less likely than men to be up-to-date with their CRC screening. ${ }^{4-11}$ Therefore, it is critical to examine the CRC screening practices of physicians and nurse practitioners (NPs) who routinely provide primary care to women. Studies have shown that 38\%-93\% of gynecologists report providing primary care to their patients. ${ }^{12-14}$ Since 1996, the Council on Resident Education in Obstetrics and Gynecology has recognized the importance of their discipline's role in women's primary healthcare and has required 6 months of primary care in their curriculum. In addition, NPs are use regularly in

\footnotetext{
${ }^{1}$ Eastern Virginia Medical School, Norfolk, Virginia.

${ }^{2}$ Division of Obstetrics/Gynecology, University of Michigan, Ann Arbor, Michigan.
} 
obstetrician/gynecologist (Ob/Gyn) practices and routinely perform health maintenance examinations. Thus, it is critical to ensure that CRC screening has been incorporated into both the $\mathrm{Ob} / \mathrm{Gyns}^{\prime}$ and NPs' preventive screening practices.

The objective of this study is to examine current CRC screening practices relative to nationally accepted guidelines and other preventive screening practices, such as mammography and cervical cancer screening, in a nationally representative sample of $\mathrm{Ob} / \mathrm{Gyns}$ and NPs.

\section{Materials and Methods}

\section{Sample population}

After attaining IRB approval at the University of Michigan, we surveyed a nationally representative sample of $\mathrm{Ob} / \mathrm{Gyns}$ and NPs in 2005-2006. The American Medical Association's Physician Masterfile was used as the sampling frame. The eligible population consisted of $\mathrm{Ob} / \mathrm{Gyns}$ and NPs aged $\leq 75$ years with an active license; 5526 individuals (1715 Ob/Gyns and 3811 NPs) met these eligibility criteria. A cross-section of the eligible population was selected using a systematic, stratified random sampling approach, which yielded 565 in each group of providers for a total of 1130 potential respondents. No information was collected on nonrespondents.

\section{Survey methods}

A survey was mailed to all 1130 potential respondents. To enhance participation, nonresponders were sent a reminder postcard 1 month after the initial survey mailing. An additional mailing to nonresponders was conducted 12 weeks after the initial survey mailing. The survey instrument was composed of 31 questions and was based on constructs from previously used surveys. ${ }^{15,16}$ Data regarding personal and practice demographics were ascertained, including sex, race/ ethnicity, practice type, community size, years in practice, percentage of primary care practice, percentage of patients aged $\geq 50$, and weekly patient volume. To assess baseline general preventive patient practices, we inquired about use of mammography, Papanicolaou (Pap) smear, and bone densitometry testing.

CRC screening methods were evaluated by determining the most frequent methods used; use of in-office vs. in-home FOBT; FOBT testing restrictions, such as avoiding meat, anticoagulants, and nonsteroidal anti-inflammatory drugs (NSAIDs); and age to initiate CRC screening in patients of various risk (i.e., with or without a family history of CRC or adenomatous polyps). Finally, we asked participants to assess CRC screening candidacy in three clinical scenarios that were representative of varying patient risk levels for CRC: patients with a history of ulcerative colitis, positive FOBT, or adenomatous polyp.

\section{Statistical analysis}

The primary outcome measure was the reported routine use of CRC screening. A secondary outcome was the reported routine use of a recommended method of CRC screening. We compared the routine use of CRC screening with routine breast and cervical cancer screening and bone densitometry testing. We then examined demographic predictors of routine use of CRC screening, including age, race/ethnicity, practice type, number of years in practice, proportion of visits classified as primary care, and the proportion of patients $\geq 50$ years.

Knowledge about CRC screening was measured by creating a summary score from answers to six individual items. These items addressed the age to start screening for an average-risk patient, age to start screening in a patient with a first-degree relative diagnosed with CRC or adenomatous polyp $<60$ and $>60$ years old, and three hypothetical clinical scenarios. The three clinical scenarios presented included a patient with a positive FOBT, a patient with a history of ulcerative colitis that affected the entire colon, and a patient with a personal history of an adenomatous polyp. Each correct answer was worth 1 point, and all other answers were worth 0 points. The total score was calculated by summing the points generated by each individual answer.

Each potential predictor variable was first examined in relation to routine use of CRC screening; bivariate analyses were performed using chi-square tests for categorical variables and Student's $t$ tests for continuous variables. Multivariable logistic regression analysis was subsequently performed to determine the adjusted odds ratios (OR) of variables that achieved bivariate statistical significance. $p$ values of $<0.05$ were considered statistically significant. All statistical analyses were done using SPSS version 13.0 (SPSS, Chicago, IL).

Table 1. Characteristics of Study Population $(N=336)^{\mathrm{a}}$

\begin{tabular}{|c|c|c|}
\hline Characteristic & $\begin{array}{l}\mathrm{Ob} / \mathrm{Gyn} \\
(\mathrm{n}=182)\end{array}$ & $\begin{array}{l}\text { Nurse practitioner } \\
\quad(\mathrm{n}=154)\end{array}$ \\
\hline \multicolumn{3}{|l|}{ Sex } \\
\hline Female* & $81(44.5 \%)$ & 150 (97.4\%) \\
\hline \multicolumn{2}{|l|}{ Age, years, ${ }^{*}$} & $50.9(8.4)$ \\
\hline \multicolumn{3}{|l|}{ Race } \\
\hline Caucasian & $150(83.7 \%)$ & $135(88.8 \%)$ \\
\hline Other & $29(16.2 \%)$ & $17(11.2 \%)$ \\
\hline \multicolumn{3}{|l|}{ Practice type } \\
\hline Private & 147 (80.1\%) & $66(42.9 \%)$ \\
\hline Multispecialty & $18(9.9 \%)$ & $11(6.0 \%)$ \\
\hline Academic & $7(3.8 \%)$ & $20(12.6 \%)$ \\
\hline $\mathrm{HMO}$ & $1(0.5 \%)$ & $8(5.2 \%)$ \\
\hline \multicolumn{3}{|l|}{ Community size } \\
\hline$<50,000$ & 34 (18.9) & $34(22.3)$ \\
\hline $51,000-100,000$ & $37(20.1)$ & 48 (31.6) \\
\hline$>100,000$ & $109(60.6)$ & $70(46.1)$ \\
\hline \multicolumn{3}{|l|}{ Years practicing* } \\
\hline$<5$ & $8(4.4)$ & $13(8.4)$ \\
\hline $5-10$ & $4(2.2)$ & $34(22.1)$ \\
\hline$>10$ & $169(92.9)$ & 107 (69.5) \\
\hline $\begin{array}{l}\% \text { of visits classified as } \\
\text { primary care, mean (SD)* }\end{array}$ & $38.6 \%(33.7)$ & $29.0 \%(32.4)$ \\
\hline $\begin{array}{l}\text { No. who provide primary } \\
\text { care }\end{array}$ & $157(86.3)$ & $126(81.8 \%)$ \\
\hline $\begin{array}{l}\text { Patients seen per week, } \\
\text { mean number }(\mathrm{SD})^{*}\end{array}$ & $70.0(31.8)$ & $60.7(34.4)$ \\
\hline $\begin{array}{l}\% \text { of patients } \geq 50 \text { years, } \\
\text { mean }(\mathrm{SD})^{*}\end{array}$ & $42.5 \%(23.5)$ & $20.7 \%(23.5)$ \\
\hline
\end{tabular}

${ }^{*} p<0.05$.

${ }^{a}$ Numbers may not equal $100 \%$ because of multiple or missing answers by respondents. 


\section{Results}

\section{Characteristics of study population}

Of the 1130 potential respondents, 336 (29.7\%) returned the mailed survey. The study population comprised $182(54 \%)$ $\mathrm{Ob} /$ Gyns and $154(46 \%)$ NPs. Characteristics of the study population are described in Table 1. Overall, most respondents were Caucasian $(84.8 \%)$, worked in private practice settings $(63.4 \%)$, and had been in practice for $>10$ years $(82.1 \%)$. Compared with NPs, a greater proportion of the $\mathrm{Ob} / \mathrm{Gyns}$ were male, older, worked in private practice settings, worked in larger communities, had been in practice for $>10$ years, and cared for an older patient population.

\section{Preventive screening practices}

Routine screening practices of $\mathrm{Ob} / \mathrm{Gyns}$ and NPs are shown in Table 2. A significantly larger proportion of $\mathrm{Ob} /$ Gyns (87.2\%) reported ordering or performing CRC screening compared with only $61.7 \%$ of NPs $(p<0.01)$. However, CRC screening was ordered less than mammography and cervical cancer screening among both provider groups, but more frequently than cholesterol and bone mineral density (BMD) screening. Routine CRC screening was significantly associated with routine use of other preventive screening practices $(p<0.001)$.

\section{Practitioner personal preferences}

Respondents were asked to indicate their preferences for their own personal CRC screening; 67\% preferred colonoscopy. Sixty-three percent of Ob/Gyns and $24 \%$ of NPs had themselves already undergone a colonoscopy or FOBT by the time of the survey.

\section{CRC screening method used and follow-up of positive screening tests}

Overall, the most common CRC screening methods used for patients were FOBT and colonoscopy $(76.2 \%$ and $28.3 \%$, respectively). A significantly larger proportion of $\mathrm{Ob} / \mathrm{Gyns}$ $(37.0 \%)$ reported ordering colonoscopy compared with only $19.8 \%$ of NPs $(p<0.005)$. Sixty-eight percent of providers performed FOBT using in-office digital rectal examination; $30 \%$ reported using in-office digital rectal examination exclusively as their CRC screening modality. Of the remaining respondents, $15 \%$ of providers used in-home FOBT exclusively

Table 2. Screening Methods Reported by Obstetrician/Gynecologists (Ов/Gyn) AND Nurse Practitioners (NP)

\begin{tabular}{lrr}
\hline Routine screening practices & $\begin{array}{c}\text { Ob/Gyn } \\
(\mathrm{n}=182)\end{array}$ & \multicolumn{1}{c}{$\begin{array}{c}N P \\
(\mathrm{n}=154)\end{array}$} \\
\hline Order CRC screening* & $157(87.2 \%)$ & $95(61.7 \%)$ \\
Mammography* & $178(98.9 \%)$ & $140(90.9 \%)$ \\
Cervical cancer screening* & $176(97.8 \%)$ & $145(94.8 \%)$ \\
$\begin{array}{l}\text { Cholesterol } \\
\text { Order bone mineral } \\
\quad \text { densitometry (DEXA)* }\end{array}$ & $95(52.8 \%)$ & $64(42.1 \%)$ \\
Correct screening method & $129(71.7 \%)$ & $72(47.1 \%)$ \\
\hline
\end{tabular}

${ }^{*} p<0.01$ and $36 \%$ used both in-home and in-office FOBT. If a patient's FOBT was positive, $61 \%$ of providers indicated they would refer for colonoscopy, yet $21 \%$ would repeat the FOBT. Although most providers reported screening routinely for CRC, many were not correctly using the five recommended screening methods and did not respond to positive testing in accordance to current recommendations.

\section{CRC screening knowledge}

Table 3 shows providers' performance on survey items measuring knowledge. Overall, $55.4 \%$ of providers identified the correct age (50 years) to initiate CRC screening in patients of average risk; one third (33.2\%) of respondents thought CRC screening should be initiated at 40 years of age, and $8.2 \%$ thought that it should be initiated at 45 years of age. Generally, $\mathrm{Ob} / \mathrm{Gyns}$ performed better than NPs on most items. Most providers in either group were unable to identify the correct age to begin screening in patients with a first-degree relative with CRC/polyps at age $>60$. Fifty-five percent of providers thought that it was never appropriate to discontinue

Table 3. CRC Screening Knowledge AMONG OBSTETRICIAN/GyneCOLOGISTS AND NuRse Practitioners

\begin{tabular}{|c|c|c|}
\hline \multirow[b]{2}{*}{$\begin{array}{l}\text { Knowledge item } \\
\text { (correct answer) }\end{array}$} & \multicolumn{2}{|c|}{$\%$ Correct answers } \\
\hline & $\mathrm{Ob} / \mathrm{Gyn}(\%)$ & $\begin{array}{c}\text { Nurse } \\
\text { practitioner (\%) }\end{array}$ \\
\hline $\begin{array}{l}\text { Age to begin screening } \\
\text { for average risk } \\
\text { patient (age 50) }\end{array}$ & $104(57.1)$ & $82(53.2)$ \\
\hline $\begin{array}{l}\text { Age to begin screening } \\
\text { in patient with two } \\
\text { or more } 1 \text { st-degree } \\
\text { relatives of any } \\
\text { age or } 1 \text { st-degree } \\
\text { relative }<60 \text { with } \\
\text { CRC or polyps } \\
\text { (age } 40)\end{array}$ & 137 (75.3) & $117(76.0)$ \\
\hline $\begin{array}{l}\text { Evaluation of } \\
\text { average risk patient } \\
\text { with positive FOBT* } \\
\text { (colonoscopy) }\end{array}$ & $173(95.1)$ & $126(81.8)$ \\
\hline $\begin{array}{l}\text { Screening frequency } \\
\text { in patient with } \\
\text { ulcerative pancolitis } \\
>10 \text { years* (every } \\
1-2 \text { years with } \\
\text { colonoscopy) }\end{array}$ & $173(95.1)$ & $134(87.0)$ \\
\hline $\begin{array}{l}\text { Evaluation of patient } \\
\text { with adenomatous } \\
\text { polyp diagnosed } \\
>10 \text { years ago* } \\
\text { (colonoscopy) }\end{array}$ & $176(96.7)$ & 137 (88.9) \\
\hline $\begin{array}{l}\text { Age to begin screening } \\
\text { in patient with } \\
\text { 1st-degree relative with } \\
\text { CRC/polyps at age } \\
\geq 60 \text { (age } 40 \text { ) }\end{array}$ & $76(41.6)$ & $65(42.2)$ \\
\hline $\begin{array}{l}\text { Knowledge score, } \\
\text { mean, SD }\end{array}$ & $4.36(1.11)$ & $4.09(1.32)^{*}$ \\
\hline
\end{tabular}


CRC screening regardless of age. There was a significant correlation between knowledge and routine CRC screening (correlation coefficient $=0.289, p<0.01$ ) but not between knowledge and screening using a recommended method. Even after adjusting for provider type, years in practice, and practice type, this relationship remained statistically significant $(p<0.001)$.

\section{Provider factors associated with CRC screening}

Several provider and practice factors were significantly associated with routine CRC screening in bivariate analyses, including provider type, provider sex, multispecialty practice type, greater number of years in practice, greater proportion of patient $\geq 50$, higher mean number of visits per week, and high proportion of visits characterized as primary care $(p<0.02$ for each variable). After adjusting for factors achieving bivariate significance, providers in multispecialty groups were 2.62 times more likely to report routine CRC screening compared with those in single specialty private practices (95\% confidence interval [CI] 1.21-5.68). The adjusted OR of routine screening for a 1 percentage point increase in the proportion of patients $>50$ years old was 0.981 (95\% CI 0.967-0.996), which corresponds to an approximately $17 \%$ decrease in the likelihood of routine screening for every 10 percentage point increase in the proportion of patients $>50$ years old. Those in practice between 5 and 10 years were 2.56 times more likely to report routine screening than those in practice $>10$ years (95\% CI 1.1-5.97). Provider gender was not associated with routine screening, but males were less likely than females to report using a recommended screening method (OR 0.41, $p<0.005$ ). Finally, there was no difference in reported rates of routine screening between NPs and $\mathrm{Ob} / \mathrm{Gyns}$, although NPs were less likely to report using a recommended screening method than Ob/Gyns $(p<0.001)$.

\section{Discussion}

Improving CRC screening practices is an initiative promoted by several professional societies, including the American College of Obstetricians and Gynecologists (ACOG). This study is the first to describe current CRC screening practices and knowledge among $\mathrm{Ob} / \mathrm{Gyns}$ and NPs in light of the most recent practice guidelines. ${ }^{2}$ Our findings suggest that both provider knowledge and screening practices need improvement, particularly with regard to FOBT use.

Our findings are similar to those of studies of other physicians. In two national surveys of primary care physicians, $85.1 \%-98 \%$ of participants recommended CRC screening. ${ }^{16,17}$ In contrast, screening rates among gastroenterologists are reported to be as high as $98 \% .{ }^{15}$ However, NPs in our study reported lower screening rates than in previous studies. In 2000 , Shaheen et al. ${ }^{18}$ conducted a survey of NPs and physician assistants. They reported $69 \%$ of primary care NPs reported recommending flexible sigmoidoscopy and $92 \%$ reported performing FOBT.

Current recommendations regarding FOBT testing include two samples from three consecutive stools that are not rehydrated using either a guaiac-based test with dietary restriction (avoiding red meat) or an immunochemical test without dietary restriction. ${ }^{19}$ For both $\mathrm{Ob} /$ Gyns and NPs in our sample, FOBT $(66 \%)$ was the diagnostic modality most often used for screening, but it appears that many are not using it as recommended. Almost one third of participants reported relying on a single stool sample obtained by in-office digital rectal examination as their screening modality. Similarly, $\mathrm{Mu}-$ sinski ${ }^{20}$ reported in a retrospective study of gynecology patients that $43 \%$ of CRC screening consisted of a single digital FOBT. Single-sample digital rectal examination appears to be a common practice of other primary care providers as well. ${ }^{21}$ The sensitivity of single digital FOBT is markedly lower $(4.9 \%)$ than that of home FOBT kits $(23.9 \%)$, which assess two samples from three consecutive stools. ${ }^{21}$ Further, $66 \%$ of practitioners in our study rehydrated stool samples, which is not recommended in the current guidelines because it decreases the performance of the assay. ${ }^{19}$ Finally, $43 \%$ of those surveyed failed to include dietary restrictions when using guaiac-based FOBT, and a similar proportion reported withholding NSAIDs, although there are no recommendations to do so. ${ }^{19}$

The effectiveness of FOBT as a CRC screening tool is determined in part by additional testing, specifically, ordering a colonoscopy when a positive test occurs. One fifth of our study participants would repeat the FOBT after a positive result, which is similar to respondents elsewhere. ${ }^{21}$ Because important lesions may bleed only intermittently, confirmatory FOBT could miss clinically important lesions. ${ }^{22}$ Therefore, follow-up of all positive tests with colonoscopy is indicated. ${ }^{19,22}$

Despite the fact that FOBT was the most commonly used modality, providers preferred colonoscopy for themselves. This discordance could be explained by a number of factors, including convenience of FOBT, cost, availability or risks of colonoscopy, and patient compliance. Klabunde et al. ${ }^{23}$ demonstrated from the 2000 National Health Interview Survey that $46 \%$ of primary care providers cited cost and lack of insurance as one of the major barriers to CRC screening. In a recent survey of primary care providers in Wisconsin, $68.5 \%$ cited cost as the major reason for not recommending colonoscopy, and $33.2 \%$ and $26.1 \%$ reported a lack of availability or risk of perforation, respectively, as barriers to colonoscopy. ${ }^{24}$ Providers' expectation of low patient compliance might also explain the relatively low use of colonoscopy. However, providers are not particularly good at determining which features of a diagnostic test are important to patients and affect their compliance. ${ }^{25}$

Clearly, opportunities for improving knowledge about CRC screening exist. For instance, only slightly more than half $(54.6 \%)$ of our respondents were able to identify the correct age to initiate screening in average-risk patients. Performance in our study was only slightly better than in a 1997 study of primary care providers $(48.5 \%)$ but worse than a 1999 survey of gastroenterologists (71\%). ${ }^{15,16}$ Our findings are disheartening, as CRC screening guidelines for average-risk populations have been available since 1997. As demonstrated by our and others' findings, further education is needed to improve screening for patients at increased risk for CRC. ${ }^{24,26}$

We found three provider factors that appeared to be positively associated with CRC screening. After controlling for other influencing factors, practitioners in multispecialty groups were 2.62 times more likely to report routine CRC screening compared with those in single specialty private practices. This may be due to enforcement of practice standards as a result of managed care or group economics. We also found that providers in practice between 5 and 10 years 
were more likely to report screening than other groups, which is consistent with other studies suggesting recent graduates are more likely to screen for CRC than those in practice $>10$ years. ${ }^{27,28}$ In previous work, provider gender has also been shown to affect patient CRC screening adherence. Menees et al. ${ }^{29}$ demonstrated that having a female physician was associated with increased prevalence of CRC screening at the time of upper endoscopy (EGD) and increased CRC screening completion in the following 6 months. Other studies have suggested that patients of female physicians were more likely to undergo breast and cervical cancer screening than those with male physicians. ${ }^{30,31}$ Although female providers in our study were not more likely to report screening than males, they were more likely to report using a recommended method. This result supports previous findings, where women physicians have been found to be more focused on prevention than their male counterparts and have more favorable views and beliefs on prevention. ${ }^{32-34}$

This study sampled practicing Ob/Gyns and NPs from the American Medical Association's membership list. However, this group may not represent the larger group of practicing $\mathrm{Ob} / \mathrm{Gyns}$ or NPs in this country. A more representative sample of $\mathrm{Ob} / \mathrm{Gyns}$ would probably be obtained by sampling members of the ACOG, but their membership lists were not available. When compared with studies of ACOG members, our sample tended to be slightly older but had a similar proportion of female physicians. Further, respondents in our study and in other studies of ACOG members tend to be in practice for $\geq 10$ years. $^{35,36}$

We also acknowledge several other study limitations. First, the low response rate (29\%) limits the generalizability of our findings, but it is reassuring that our responses were fairly consistent with studies of other provider types, some of which might be expected to be more knowledgeable about CRC screening than $\mathrm{Ob} / \mathrm{Gyns}$. Additionally, as those who respond to surveys are typically thought to have a particular interest or knowledge in the study topic, we would expect that our sample would perform better than nonresponders. Therefore, our results probably do not underestimate screening practices or knowledge about CRC screening. Additionally, reporting bias may be present in these data because we are relying on self-reported data. Again, we would expect that influence to result in an overestimate of CRC screening practices. Other studies have shown that clinicians overestimate their cancer screening practices. ${ }^{37-39}$

\section{Conclusions}

Our results demonstrate important CRC screening patterns among $\mathrm{Ob} / \mathrm{Gyns}$ and NPs. Routine screening for CRC among $\mathrm{Ob} / \mathrm{Gyns}$ and NPs is less frequent than screening for other cancers, such as breast cancer or cervical cancer. Even though up to $80 \%$ of surveyed providers reported performing routine CRC screening, only $59 \%$ routinely screen following recommended guidelines, and $53 \%$ were able to identify the correct age to initiate screening. The incorrect use of FOBT is prevalent especially among $\mathrm{Ob} / \mathrm{Gyns}$, as is inadequate follow-up of positive FOBT results. As many women seek primary care from $\mathrm{Ob} / \mathrm{Gyns}$ and NPs, further education of both healthcare providers and patients may improve compliance with current CRC screening guidelines.

\section{Acknowledgments}

An Abstract of this work was presented at the ACOG meeting in San Diego, California, May 2007.

\section{Disclaimer Statement}

The authors have no conflicts of interest to report.

\section{References}

1. Jemal A, Siegel R, Ward E, Murray T, Xu J, Thun MJ. Cancer statistics, 2007. CA Cancer J Clin 2007;57:43-66.

2. Levin B, Lieberman DA, McFarland B, et al. Screening and surveillance for the early detection of colorectal cancer and adenomatous polyps, 2008: A joint guideline from the American Cancer Society, the U.S. Multi-Society Task Force on Colorectal Cancer, and the American College of Radiology. CA Cancer J Clin 2008;58:130-160.

3. Increased use of colorectal cancer tests-United States, 2002 and 2004. MMWR 2006;55:308-311.

4. Rao RS, Graubard BI, Breen N, Gastwirth JL. Understanding the factors underlying disparities in cancer screening rates using the Peters-Belson approach: Results from the 1998 National Health Interview Survey. Med Care 2004;42:789800.

5. Straus WL, Mansley EC, Gold KF, Wang Q, Reddy P, Pashos $\mathrm{CL}$. Colorectal cancer screening attitudes and practices in the general population: a risk-adjusted survey. I Public Health Manag Pract 2005;11:244-251.

6. Chao A, Connell CJ, Cokkinides V, Jacobs EJ, Calle EE, Thun MJ. Underuse of screening sigmoidoscopy and colonoscopy in a large cohort of U.S. adults. Am J Public Health 2004; 94:1775-1781.

7. Etzioni DA, Ponce NA, Babey SH, et al. A population-based study of colorectal cancer test use: Results from the 2001 California Health Interview Survey. Cancer 2004;101:25232532.

8. Farraye FA, Horton K, Hersey H, Trnka Y, Heeren T, Provenzale D. Screening flexible sigmoidoscopy using an upper endoscope is better tolerated by women. Am J Gastroenterol 2004;99:1074-1080.

9. Bressler B, Lo C, Amar J, et al. Prospective evaluation of screening colonoscopy: Who is being screened? Gastrointest Endosc 2004;60:921-926.

10. Slattery ML, Kinney AY, Levin TR. Factors associated with colorectal cancer screening in a population-based study: The impact of gender, health care source, and time. Prev Med 2004;38:276-283.

11. Turner B, Myers RE, Hyslop T, et al. Physician and patient factors associated with ordering a colon evaluation after a positive fecal occult blood test. J Gen Intern Med 2003;18: 357-363.

12. Gonik B, Jones T, Contreras D, Fasano N, Roberts C. The obstetrician-gynecologist's role in vaccine-preventable diseases and immunization. Obstet Gynecol 2000;96:81-84.

13. Kirk EP, Santa J, Heckler T, Collins M. Obstetriciangynecologists as primary care physicians: The Oregon experience-Early perceptions regarding the effects of legislative action. Am J Obstet Gynecol 1998;178:1222-1228.

14. Morrison JC, Cowan BD, Hampton HL, Morton HH, Martin JN Jr, McGehee RP. Medical practices of past graduates from one obstetric/gynecologic training program. South Med J 1998;91:227-230. 
15. Sharma VK, Corder FA, Fancher J, Howden CW. Survey of the opinions, knowledge, and practices of gastroenterologists regarding colorectal cancer screening and use of the fecal occult blood test. Am J Gastroenterol 2000;95:36293632.

16. Sharma VK, Vasudeva R, Howden CW. Colorectal cancer screening and surveillance practices by primary care physicians: Results of a national survey. Am J Gastroenterol 2000;95:1551-1556.

17. Klabunde CN, Frame PS, Meadow A, Jones E, Nadel M, Vernon SW. A national survey of primary care physicians' colorectal cancer screening recommendations and practices. Prev Med 2003;36:352-362.

18. Shaheen NJ, Crosby MA, O'Malley MS, et al. The practices and attitudes of primary care nurse practitioners and physician assistants with respect to colorectal cancer screening. Am J Gastroenterol 2000;95:3259-3265.

19. Winawer S, Fletcher R, Rex D, et al. Colorectal cancer screening and surveillance: Clinical guidelines and rationale-Update based on new evidence. Gastroenterology 2003;124:544-560.

20. Musinski SE. Colorectal cancer screening by obstetriciangynecologists. Am J Obstet Gynecol 2001;184:1054-1056.

21. Collins JF, Lieberman DA, Durbin TE, Weiss DG. Accuracy of screening for fecal occult blood on a single stool sample obtained by digital rectal examination: A comparison with recommended sampling practice. Ann Intern Med 2005; 142:81-85.

22. Ransohoff DF, Lang CA. Screening for colorectal cancer with the fecal occult blood test: A background paper. American College of Physicians. Ann Intern Med 1997;126: 811-822.

23. Klabunde CN, Vernon SW, Nadel MR, Breen N, Seeff LC, Brown ML. Barriers to colorectal cancer screening: A comparison of reports from primary care physicians and average-risk adults. Med Care 2005;43:939-944.

24. Taylor ML, Anderson R. Colorectal cancer screening: Physician attitudes and practices. WMJ 2002;101:39-43.

25. Ling BS, Moskowitz MA, Wachs D, Pearson B, Schroy PC. Attitudes toward colorectal cancer screening tests. J Gen Intern Med 2001;16:822-830.

26. Barrison AF, Smith C, Oviedo J, Heeren T, Schroy PC 3rd. Colorectal cancer screening and familial risk: A survey of internal medicine residents' knowledge and practice patterns. Am J Gastroenterol 2003;98:14101416.

27. Lewis JD, Asch DA, Ginsberg GG, et al. Primary care physicians' decisions to perform flexible sigmoidoscopy. I Gen Intern Med 1999;14:297-302.
28. Schroy PC 3rd, Geller AC, Crosier Wood M, et al. Utilization of colorectal cancer screening tests: A 1997 survey of Massachusetts internists. Prev Med 2001;33:381-391.

29. Menees SB, Scheiman J, Carlos R, Mulder A, Fendrick AM. Gastroenterologists utilize the referral for EGD to enhance colon cancer screening more effectively than primary care physicians. Aliment Pharmacol Ther 2006;23:953-962.

30. Lurie N, Margolis KL, McGovern PG, Mink PJ, Slater JS. Why do patients of female physicians have higher rates of breast and cervical cancer screening? J Gen Intern Med 1997;12:34-43.

31. Henderson JT, Weisman CS. Physician gender effects on preventive screening and counseling: An analysis of male and female patients' health care experiences. Med Care 2001;39:1281-1292.

32. Frank E, Harvey LK. Prevention advice rates of women and men physicians. Arch Fam Med 1996;5:215-219.

33. Maheux B, Dufort F, Beland F, Jacques A, Levesque A. Female medical practitioners. More preventive and patient oriented? Med Care 1990;28:87-92.

34. Bertakis KD, Helms LJ, Callahan EJ, Azari R, Robbins JA. The influence of gender on physician practice style. Med Care 1995;33:407-416.

35. Chamany S, Schulkin J, Rose CE Jr, Riley LE, Besser RE. Knowledge, attitudes, and reported practices among obstetrician-gynecologists in the USA regarding antibiotic prescribing for upper respiratory tract infections. Infect Dis Obstet Gynecol 2005;13:17-24.

36. Power ML, Schulkin J, Rossouw JE. Evolving practice patterns and attitudes toward hormone therapy of obstetriciangynecologists. Menopause 2007;14:20-28.

37. Montano DE, Phillips WR. Cancer screening by primary care physicians: A comparison of rates obtained from physician self-report, patient survey, and chart audit. Am J Public Health 1995;85:795-800.

38. Woo B, Woo B, Cook EF, Weisberg M, Goldman L. Screening procedures in the asymptomatic adult. Comparison of physicians' recommendations, patients' desires, published guidelines, and actual practice. JAMA 1985;254:1480-1484.

39. Hall HI, Van Den Eeden SK, Tolsma DD, et al. Testing for prostate and colorectal cancer: Comparison of self-report and medical record audit. Prev Med 2004;39:27-35.

Address correspondence to: Stacy B. Menees, M.D. 885 Kempsville Road, Suite 114 Norfolk, VA 23502

E-mail: Sbartnik@gmail.com 